\title{
$\mathrm{PPG} \operatorname{LinC}(10$
}

\section{ESCRITA NO BRASIL QUINHENTISTA: UMA ANÁLISE DAS GRAFIAS NOS LIVROS DA PRIMEIRA VISITAÇÃO DO TRIBUNAL DA INQUISIÇÃO EM PERNAMBUCO, ITAMARACÁ E PARAÍBA}

\begin{abstract}
WRITING IN SIXTEENTH-CENTURY BRAZIL: AN ANALYSIS OF THE GRAPHICS IN THE BOOKS OF THE FIRST VISITATION OF THE COURT OF INQUISITION IN PERNAMBUCO, ITAMARACÁ AND PARAÍBA
\end{abstract}

\author{
Ana Sartori ${ }^{1}$ \\ Universidade Federal da Bahia
}

Resumo: Tomando-se como base os livros produzidos durante a Primeira Visitação da Inquisição Portuguesa ao Brasil, é realizada uma análise de aspectos da escrita no início da colonização brasileira. Aqui são abordadas as grafias, os sinais abreviativos e os sinais diacríticos de dois dos livros da Primeira Visitação: o Quarto Livro de Denunciações e o Terceiro Livro de Confissões, ambos redigidos ao final do século XVI, durante a visita às Capitanias de Pernambuco, Itamaracá e Paraíba. As mãos que redigiram os referidos livros são a do notário do Santo Ofício, Manuel Francisco, e a do visitador, Heitor Furtado de Mendonça. Os aspectos da escrita analisados são ilustrados através de quadros, em que se apresentam imagens retiradas dos fac-similes dos manuscritos, que se encontram disponíveis no site do Arquivo Nacional da Torre do Tombo, arquivo onde estão atualmente depositados os originais.

Palavras-chave: Escrita; Brasil colonial; Livros da Inquisição.

1 anasartorii@hotmail.com 


\begin{abstract}
Based on the books produced during the First Visit of the Portuguese Inquisition to Brazil, an analysis of aspects of writing at the beginning of Brazilian colonization is carried out. Here the graphics, abbreviated signs and diacritical signs from two of the nine books reporting the First Visitation are addressed: the Fourth Book of Denunciations and the Third Book of Confessions, both written at the end of the 16th century, during the visit to the Captaincies of Pernambuco, Itamaracá and Paraiba. The hands that wrote these books are the one from the Holy Office's notary, Manuel Francisco, and the other from the visitor, Heitor Furtado de Mendonça. The analyzed aspects of writing are illustrated through tables, in which images taken from the facsimiles of the manuscripts are presented, which are available on the website of the National Archive of Torre do Tombo, the archive where the originals are currently deposited.
\end{abstract}

Keywords: Writing; Colonial Brazil; Inquisition books.

\title{
INTRODUÇÃO
}

Do ano de 1591 a 1596, ocorreu a primeira visitação do Tribunal da Inquisição Portuguesa ao Brasil. O visitador do Santo Ofício, Heitor Furtado de Mendonça, visitou as capitanias da Bahia, Pernambuco, Itamaracá e Paraíba, acompanhado pelo notário do Santo Ofício, Manuel Francisco, que tinha como missão registrar, nos livros do Santo Ofício, tudo o que se passava nos depoimentos prestados pela população perante a mesa do Tribunal. Após ter sido registrada pelo notário a denúncia ou a confissão feita, o notário solicitava à testemunha que assinasse o depoimento transcrito, como forma de confirmar e validar o registro.

O registro das assinaturas deixadas pela população nos livros do Santo Ofício faz desses documentos uma valiosa fonte de estudo a respeito da difusão da escrita no Brasil colonial, uma vez que, entre os depoentes, que são uma representativa amostra da população colonial, é possível mensurar quem sabia e quem não assinar o nome e ainda avaliar um certo nível de execução gráfica, de acesso às práticas de escrita, a partir da qualidade das assinaturas traçadas.

Em um contínuo do nível de letramento da população colonial estariam, em uma ponta, os depoentes que não sabiam sequer assinar o próprio nome, como era o caso dos indivíduos escravizados, alheados de diversas práticas 
sociais e culturais, entre elas o acesso à leitura e à escrita, e era também a situação em que se encontravam muitas mulheres, incapazes de assinar o nome, já que a escrita era considerada uma prática inútil e perigosa para o sexo feminino (CHARTIER, 1991, p.117). Na outra ponta do contínuo, encontravam-se os indivíduos mais letrados, que revelavam, em sua escrita, destreza, fluidez e um grande domínio dos tipos gráficos registrados nos manuais de caligrafia da época. Entre eles, encontravam-se muitos dos religiosos, os quais dominavam não só a leitura e a escrita em língua portuguesa, como também em latim, o que lhes permitia a leitura da Bíblia, já que nesse momento era proibida a leitura da Bíblia traduzida ao português.

\section{UMA ANÁLISE DAS GRAFIAS EM LIVROS DA PRIMEIRA VISITAÇÃO DA INQUISIÇÃO AO BRASIL}

Durante a primeira visitação da Inquisição ao Brasil, foram produzidos nove livros, divididos em quatro livros de denunciações, três livros de confissões e dois livros de ratificações, os quais se encontram depositados no Arquivo Nacional da Torre do Tombo (doravante, ANTT), em Portugal. Atualmente, no site do ANTT, tem-se acesso a cópias digitalizadas dos livros da Inquisição, a partir das quais foram extraídas as imagens que serão aqui apresentadas.

A análise irá se debruçar sobre a escrita de indivíduos que se encontram na ponta letrada do contínuo de acesso às práticas de leitura e escrita do nosso Brasil colonial: o notário e o visitador do Santo Ofício, principais redatores dos livros de registro da Primeira Visitação ao Brasil. Foram utilizados como corpus dois dos nove livros da Primeira Visitação, ambos produzidos nas Capitanias de Pernambuco, Itamaracá e Paraíba: o Quarto Livro de Denunciações e o Terceiro Livro 
de Confissões. ${ }^{2}$ A partir da escrita desses dois redatores nos referidos livros, serão analisadas as grafias, os sinais abreviativos e os sinais diacríticos deixados.

\section{A ESCRITA DO NOTÁRIO NOS LIVROS DA PRIMEIRA VISITAÇÃO}

A principal mão a deixar registros nos livros da Primeira Visitação da Inquisição é a do notário do Santo Ofício, Manuel Francisco. Foi ele quem redigiu, nos livros, todos os depoimentos prestados pelas testemunhas e também os registros das ações realizadas no âmbito da Visitação: relatos da viagem, das procissões e autos, dos juramentos, apresentações etc. É, portanto, da mão do notário todo o corpo dos textos dos livros da Primeira Visitação. O Quadro 1 retrata as diferentes formas de grafar as letras do notário. Em seguida, tem-se um extrato do fólio 1-recto (Fig.1), em que se pode observar a sua escrita.

2 A análise das grafias foi realizada durante a edição semidiplomática que foi feita dos referidos livros. A edição do Quarto Livro de Denunciações deu-se durante o doutoramento em Língua e Cultura pelo PPGLinC/UFBA, tendo como fruto a tese Pela pena do Santo Ofício: difusão social da escrita nas capitanias de Pernambuco, Itamaracá e Paraíba em finais Quinhentos (SARTORI, 2016). A edição do Terceiro Livro de Confissões foi realizada no âmbito do Projeto de Pesquisa por mim coordenado, intitulado Difusão social da escrita e da língua portuguesa no início da colonização do Brasil. 
Quadro 1: Grafias do notário Manuel Francisco

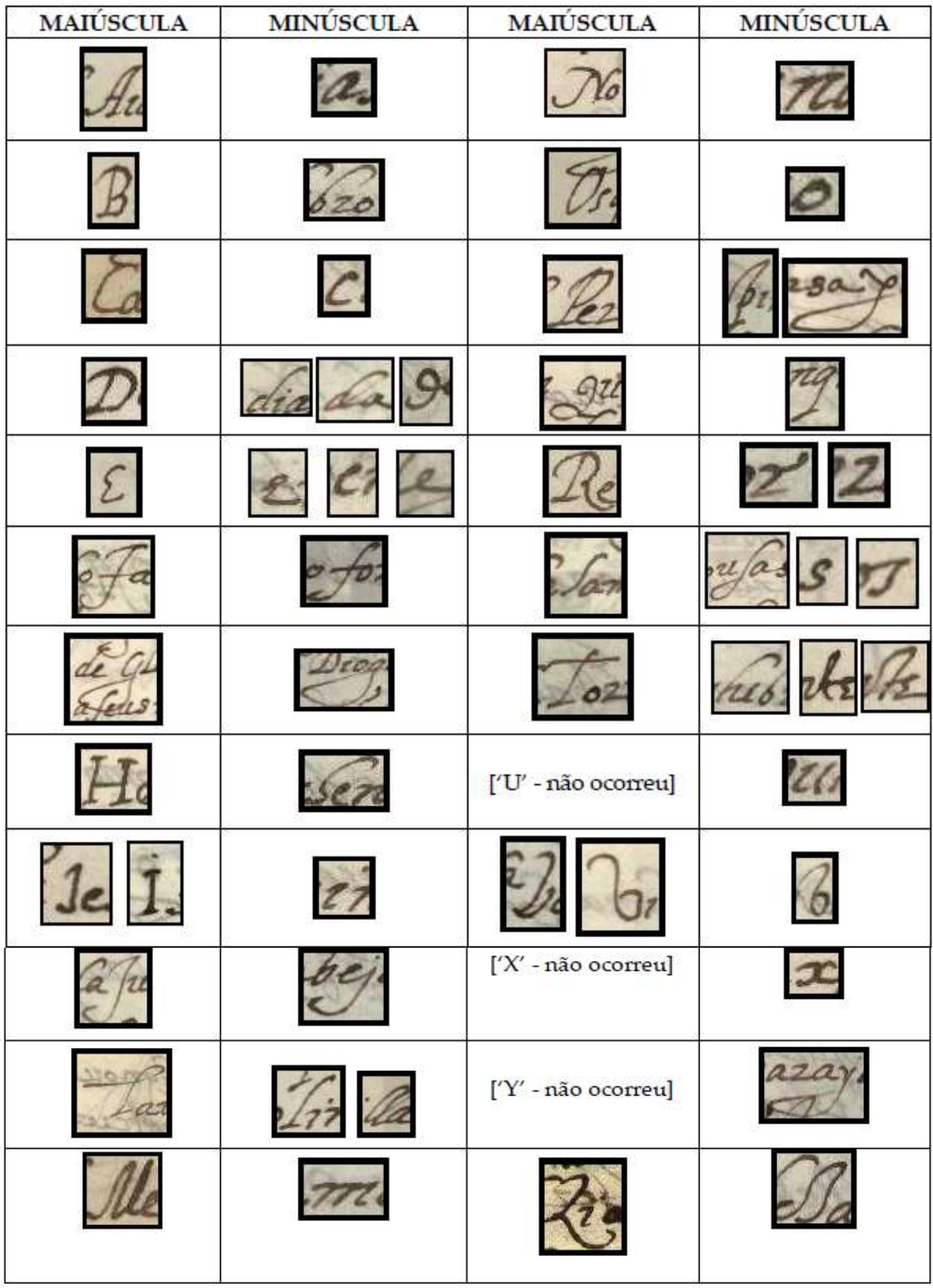

Fonte: Adaptado de Sartori (2016, p. 295-296) 
Figura 1: Fragmento do fólio 1-recto do Quarto Livro das Denunciações

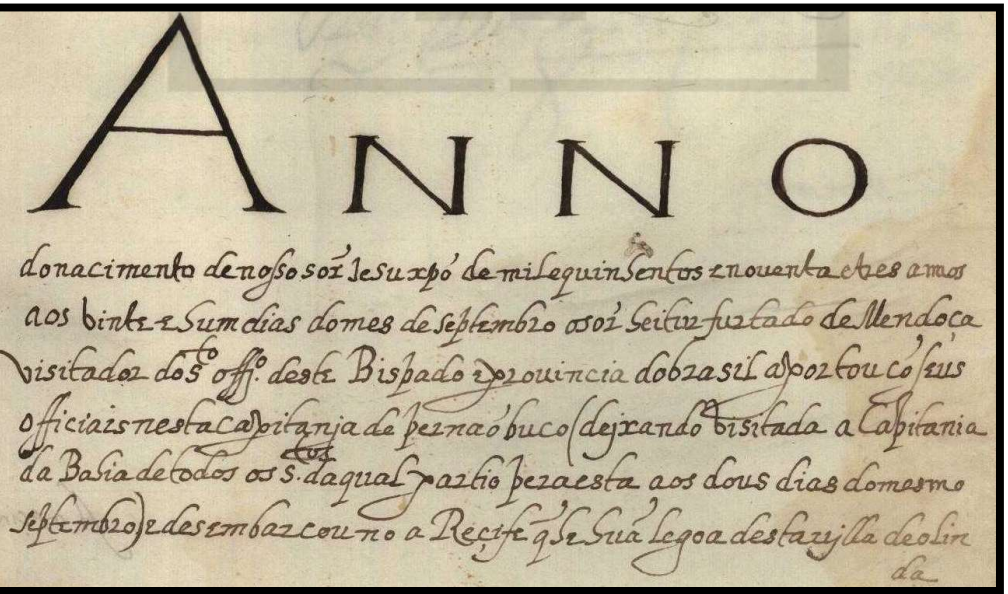

Fonte: Quarto Livro das Denunciações, fol. 01r

\subsection{Análise da escrita do notário}

A letra do notário é uma humanística do tipo italiana de chancelaria (STEFFENS, 1910, p. 122), também chamada de cursiva chanceleresca (LEAL, 2011, p. 36). Trata-se de uma variedade da cursiva humanística. Seu traçado é cursivo, como não poderia deixar de ser o traçado de um livro da sua extensão, para o qual não haveria muito tempo para a redação, já que ele foi elaborado em conjunto com outros oito longos livros feitos pelo notário durante a Primeira Visitação. Não havia, portanto, a calma que requereria uma escrita do tipo humanística dos livros, de palavras sem ligações entre as letras, e letras de traçado pouco corrente, a maioria delas exigindo mais de um traço para serem feitas. Em muitas linhas do manuscrito, as palavras são escritas todas muito juntas; às vezes, os espaços entre as letras do interior das palavras são maiores que os espaços entre as palavras.

As letras presentes no documento são, em geral, arredondadas, com hastes curvas e inclinadas para a direita - como se nota com as letras 'b', 'd' (primeira do Quadro 1), 'f', ' $h$ ', ' 1 ', 's' longo e 't' (primeira do Quadro 1). Há algumas letras 
caudadas ('f', ' 'g', 'j', ' p' , 'q', 's' longo, 'y' , 'z') e algumas letras com hastes apoiadas em traços horizontais (letra ' $\mathrm{q}$ ', o ' $\mathrm{p}$ ' reto, ' $\mathrm{v}$ ' e o ' $\mathrm{t}$ ' não curvado - terceiro do Quadro 1), sendo essa última uma característica típica da letra italiana de chancelaria, que faz com que essa escrita seja também chamada em italiano de 'testegiatta', por possuir 'testas' apoiadas nas hastes (STEFFENS, 1910, p. XXV4). As serifas nas hastes por vezes são usadas para ligar uma letra a outra; por vezes, não.

O notário inicia a escrita, no fólio 1-recto (ver Fig. 1), com uma letra mais vertical e com poucas ligações entre as letras. A partir da segunda linha, sua escrita vai se tornando mais inclinada, e ao final do fólio já se nota uma escrita bastante inclinada para a direita e cheia de letras ligadas, escrita que irá predominar em todo o documento. $\mathrm{O}$ ' $\mathrm{r}$ ' reto da primeira linha dá rapidamente lugar ao ' $r$ ' do tipo redondo, também chamado de meio ' $r$ ' (em contraposição ao ' $r$ ' inteiro), usado na escrita cursiva humanística, que é adotado da escrita gótica, havendo a particularidade de que o ' $r$ ' nesse documento é escrito geralmente com ângulos pontiagudos, assemelhando-se a um ' $z$ ' simples; muito raramente encontra-se um formato mais arredondado do ' $r$ '.

O 'p' reto, desenhado com dois traços (um para a haste e serifas, outro para o bojo da letra) das primeiras linhas, é substituído, na terceira linha, pelo ' $\mathrm{p}$ ' arredondado, mais cursivo, de um único traçado, que é o mais utilizado pelo notário, ainda que o primeiro tipo continue aparecendo ao longo de todo o documento.

O ‘a' é desde o início um 'a' cursivo simples, tipo que é adotado da cursiva gótica, da mesma forma que ocorre na escrita cursiva humanística (STEFFENS, 1910, p. 24). O 'd' geralmente utilizado é um 'd' reto, formado por dois traços, embora tenha ocorrido também mais raramente o ' $\mathrm{d}$ ' redondo, de um só traço, também advindo da cursiva gótica (segundo 'd' no Quadro 1). Ocorre ainda um 'd' mais cursivo, semelhante ao 'd' uncial (terceiro no Quadro 1). 
Veem-se diferentes tipos da letra ' $\mathrm{e}$ ', todos feitos com um único traço. A forma com traçado semelhante ao 'E' maiúsculo (primeiro do Quadro 1) parece ter sido utilizada preferentemente pelo notário ao início de palavras e na conjunção ' $\mathrm{e}$ ', enquanto as outras formas foram mais utilizadas no interior de palavras, sobretudo o 'e' que se liga à letra anterior.

$\mathrm{O}$ 's' longo e o 's' curto se alternam, sendo o 's' longo preferido no início de palavra, e o 's' curto, no final. Ocorre ainda com bastante regularidade nas palavras em que há 'ss' de o primeiro 's' ser longo e o segundo, curto. Os dois podem aparecer ligados ou não a outras letras; o 's' longo, quando possui ligamento, liga-se com a letra subsequente; o 's' curto, com a letra que o antecede, ganhando um aspecto diferente, semelhante ao 's' cursivo atual (terceiro ' $\mathrm{s}$ ' no Quadro 1).

$\mathrm{O}$ ‘ $v$ ' tem forma por vezes arredondada, por vezes levemente pontiaguda. A forma mais utilizada, porém, é o ' $u$ ', tanto com valor consonantal, quanto com valor vocálico. As formas variantes ' $i$ ' e ' $j$ ' se alternam, sendo preferido o ' $j$ ' quando se trata de semivogal.

As letras 'b', 'g' e ' $q$ ' são formadas com um só traço. As letras ' $h$ ' e ' $z$ ' possuem um desenho bastante característico, feito também com um único traço. A haste principal do ' $h$ ' não chega à linha mediana inferior. $O$ ' $z$ ' é caudado, mas a letra fica apoiada na pauta central, e sua cauda não ultrapassa o limite da linha mediana inferior, enquanto a linha mediana superior é ultrapassada. Quando o ' $\mathrm{z}$ ' se encontra ligado à letra anterior, o traçado fica bastante semelhante ao de um 's'. O traçado de ambas as letras é idêntico àquele apresentado para o tipo 'corsivo cancellaresco' no Essemplare di più sorti lettere, de Giovan Francesco Cresci (1578), o qual, segundo Clayton (2015), foi o mais influente manual de caligrafia do século XVI.

No fólio 11r, 1.09 do Quarto Livro de Denunciações, há um 'r' reto riscado sobre o meio ' $r$ ' no início da palavra 'reçebeo', indicando que seria 
provavelmente uma regra o uso do ' $r$ ' reto no início de palavra, embora o próprio notário quebre essa regra. $\mathrm{O}$ ' $\mathrm{r}$ ' redondo é o escolhido quase sempre no interior da palavra, e muitas vezes não se liga com a letra que o antecede. Ao final de palavra, parece haver uma preferência pelo uso do ' $r$ ' reto.

A base do 'l' é feita tanto pontiaguda, quanto arredondada. A primeira forma (primeira no Quadro 1) é mais utilizada em início e final de palavra, e a segunda ocorre frequentemente nos casos em que essa letra é dobrada, quando as duas letras se apresentam ligadas.

As maiúsculas possuem, em sua maioria, um traçado também cursivo, e por isso, em algumas letras, não se distingue bem a maiúscula da minúscula, sobretudo quando há uma grande oscilação de tamanho. As formas maiúsculas das letras ' $\mathrm{A}^{\prime}$, ' $\mathrm{B}^{\prime}$, ' $\mathrm{D}^{\prime}$, ' $\mathrm{H}^{\prime}$, ' $\mathrm{M}^{\prime}$, ' $\mathrm{N}^{\prime}$, ' $\mathrm{P}^{\prime}$, ' $\mathrm{R}$ ' e ' $\mathrm{Z}$ ' possuem traçado claramente diferenciado de suas respectivas minúsculas. Já as letras ' $\mathrm{C}^{\prime}$, ' $\mathrm{E}^{\prime}$, ' $\mathrm{F}^{\prime}$, ' $\mathrm{G}$ ', 'J', 'L', 'O', 'Q', 'S', ‘T' e 'V' possuem leves diferenças entre um traçado prototípico maiúsculo e um traçado prototípico minúsculo, diferenças que se apresentam na escrita de forma mais acentuada, em alguns casos, de forma bastante sutil, em outros casos, ou mesmo não se apresentam.

A curva do ' $C$ ' tende a ser mais completada na parte superior do arco na sua forma maiúscula do que na minúscula, o que não se constitui absolutamente uma regra. $\mathrm{O}$ 'E' maiúsculo é em geral mais aberto que o minúsculo de formato semelhante; o minúsculo possui muitas vezes um pequeno traço para dentro do bojo ao final do traço superior da letra. $\mathrm{O}^{\prime} \mathrm{F}^{\prime}$ maiúsculo possui uma serifa na parte superior, que é semelhante ao ' $\mathrm{f}$ ' minúsculo, quando este possui um traço na parte superior que o liga a outra letra. $\mathrm{O}$ bojo do ' $\mathrm{G}$ ' maiúsculo possui geralmente uma abertura que mais dificilmente é notada no ' $\mathrm{g}$ ' minúsculo. A haste do ' $\mathrm{J}$ ' maiúsculo ultrapassa a linha média superior, enquanto, no 'j' minúsculo, isso tende a não ocorrer, embora haja exemplos de ' $\mathrm{j}$ ' minúsculo que ultrapassam essa 
linha. Viu-se que a forma maiúscula do ' $\mathrm{j}$ ' aparece excessivamente nos manuscritos, sobretudo em início de palavras.

$\mathrm{O}$ ' $\mathrm{L}$ ' de base pontiaguda e laçada ao início da haste ocorreu muito raramente, o que deixa a impressão de que talvez o ' 1 ' sem laçada, de base pontiaguda também poderia estar representando a maiúscula. Entretanto, como essa forma é usada indistintamente, alternando-se sempre com o ' 1 ' de base arredondada, o critério aqui utilizado é de sempre considerá-la minúscula. $\mathrm{O}$ 'O' maiúsculo é em geral mais oval que o minúsculo. A forma aqui considerada como o 'Q' maiúsculo possui um traçado bastante característico, embora esta letra tenha sido desenhada entre a linha média superior e a linha inferior. A 'linha' de separação entre o ' $S$ ' maiúsculo e o 's' minúsculo é bastante tênue; o 's' longo é aqui considerado sempre minúsculo, por ter sempre a mesma forma. Foi considerado maiúsculo apenas o 's' curto que ultrapassa a linha média superior, observando-se que esse ocorreu em profusão no início dos possessivos 'seu'/'sua', e de alguns substantivos como 'Segredo', 'Sábado' e 'Santo', além de nomes próprios. $\mathrm{O}$ ' $\mathrm{T}$ ' considerado maiúsculo é aquele que possui serifa no pé, mas nota-se que essa forma ocorreu pouco no documento, enquanto se vê com alguma frequência o uso do ' $t$ ' sem serifa em tamanho grande no início de linha, posição em se que notou maior emprego de letras maiúsculas, mas tais ocorrências do ' $t$ ' foram consideradas minúsculas, por fugirem ao critério estabelecido para a forma maiúscula. $\mathrm{O}^{\prime} \mathrm{V}$ ' maiúsculo tem geralmente a base acentuadamente pontiaguda, enquanto $\mathrm{o}$ ' $\mathrm{v}$ ' minúsculo tem base mais arredondada, mas foi considerado também maiúsculo o ' $\mathrm{V}$ ' de base mais arredondada que se destacava acentuadamente do texto pelo seu tamanho.

Encontram-se maiúsculas interessantes iniciando algumas seções, sobretudo nos primeiros fólios. A letra 'A', que se vê, por exemplo, nos fólios $2 \mathrm{r}$, 2v, 3r, 3v e 4r do Quarto Livro de Denunciações (ver Fig. 2), tem um traçado cursivo e é ornada com laçadas; as demais letras são retas e possuem serifas, 
assemelhando-se ao traçado das maiúsculas imperiais, o que se pode notar, entre outras, na letra ' $\mathrm{N}$ ' do fólio $5 \mathrm{r}$ e $5 \mathrm{v}$ (ver Fig. 3) e na letra ' $\mathrm{E}$ ' do fólio 6r, também do Quarto Livro (Fig. 4), como se ver a seguir:

Figura 2: Letra A

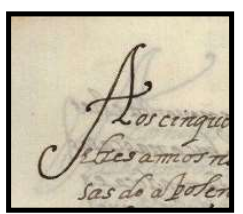

Figura 3: Letra N

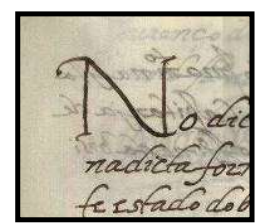

Figura 4: Letra E

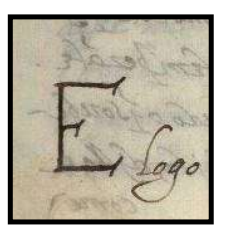

Fonte: QUARTO..., fol. 02r Fonte: QUARTO..., fol. 05r Fonte: QUARTO..., fol. 06r

\section{A ESCRITA DO VISITADOR NOS LIVROS DA PRIMEIRA VISITAÇÃO}

Nos livros produzidos durante a primeira visita do Santo Ofício ao Brasil, tem-se também uma relevante presença da mão do visitador do Santo Ofício, Heitor Furtado de Mendonça. Além da escrita do notário e do visitador, veem-se apenas as assinaturas deixadas por testemunhas presentes nos autos e por toda a população que se apresentava perante a Mesa do Tribunal para denunciar os considerados crimes religiosos ou confessar as próprias culpas, que assinava ao final do registro do depoimento prestado, como forma de validar o depoimento registrado pelo notário.

O visitador era quem preenchia no cabeçalho dos fólios, escrevendo, no recto, o local do registro, o seu sinal, 'Mendoça', e o número do fólio, e, no verso, apenas a palavra 'Brazil' (ver Fig. 5 e Fig. 6). É também da mão do visitador uma listagem feita no primeiro fólio de cada um dos livros, no qual estão listados os nove livros produzidos na primeira visitação, e ainda o termo de encerramento dos livros, presente no fólio final (ver Fig. 7). Ademais, foram escritos pelo visitador os títulos que iniciam as diversas partes do livro (ver Fig. 8) e os 
diversos lançamentos marginais à esquerda do texto central (ver Fig. 9), como se pode observar nos exemplos a seguir:

Figura 5: Cabeçalho preenchido pelo visitador

\section{Enabuco}

$$
\text { Mendocas? }
$$

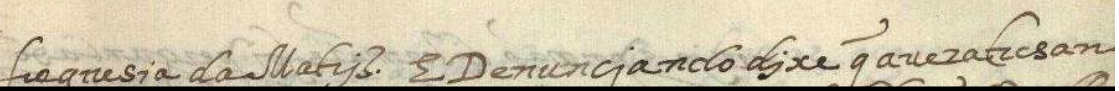

Fonte: Quarto Livro das Denunciações, fol. 17r

Figura 6: Cabeçalho preenchido pelo visitador - verso do fólio

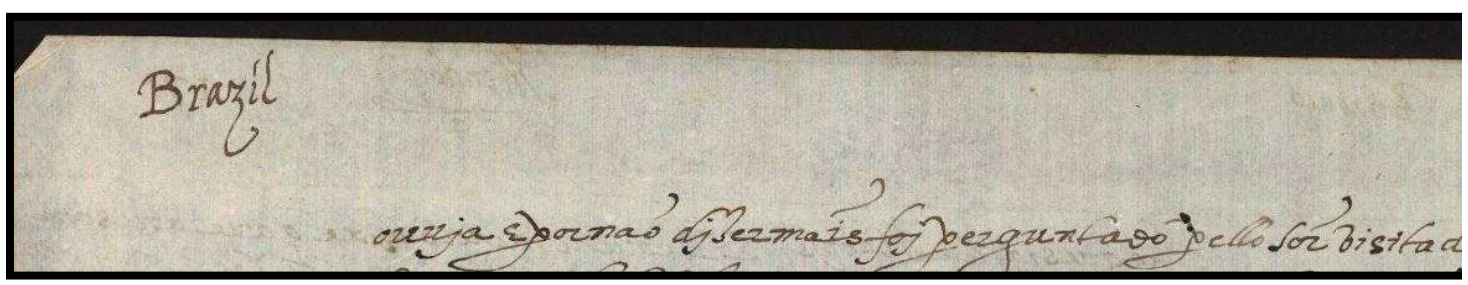

Fonte: Quarto Livro das Denunciações, fol. 17v

Figura 7: Termo de encerramento do Quarto Livro das Denunciações

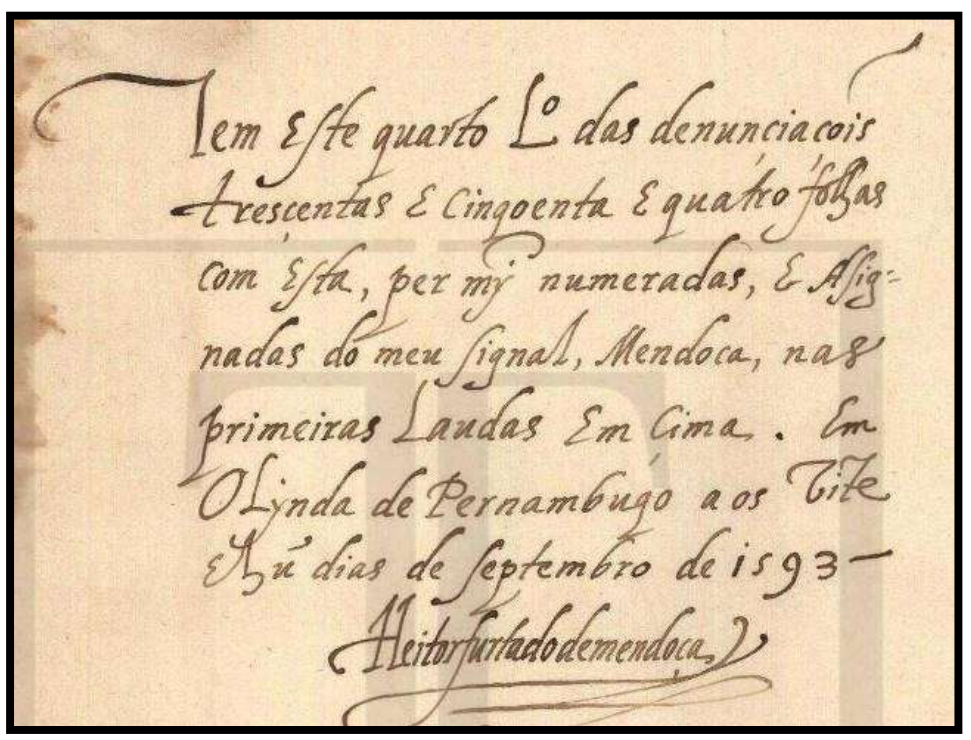

Fonte: Quarto Livro das Denunciações, fol. 354v 
Figura 8: Exemplo de título escrito pelo visitador

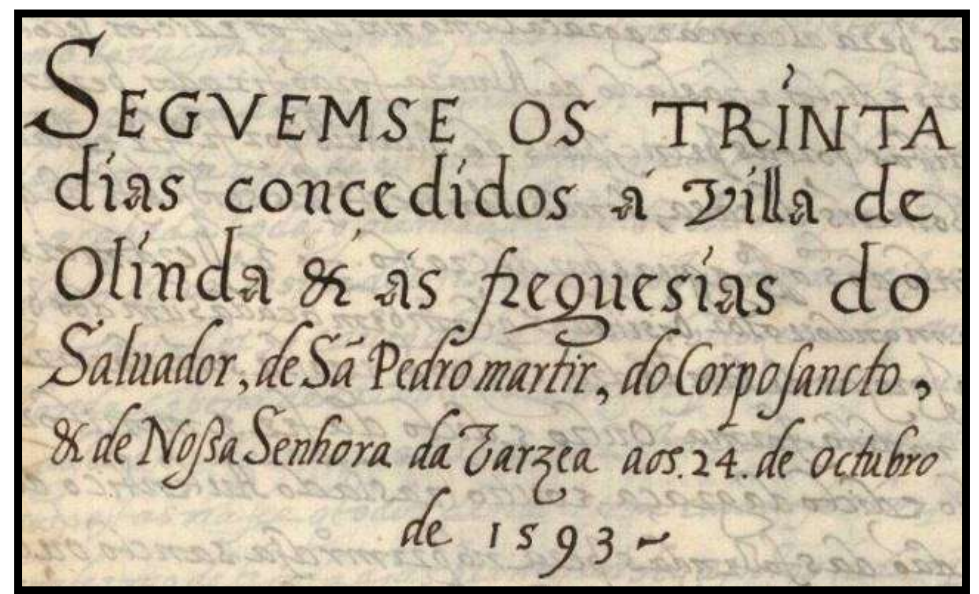

Fonte: Quarto Livro das Denunciações, fol. 07v

Figura 9: Lançamentos marginais feitos pelo visitador

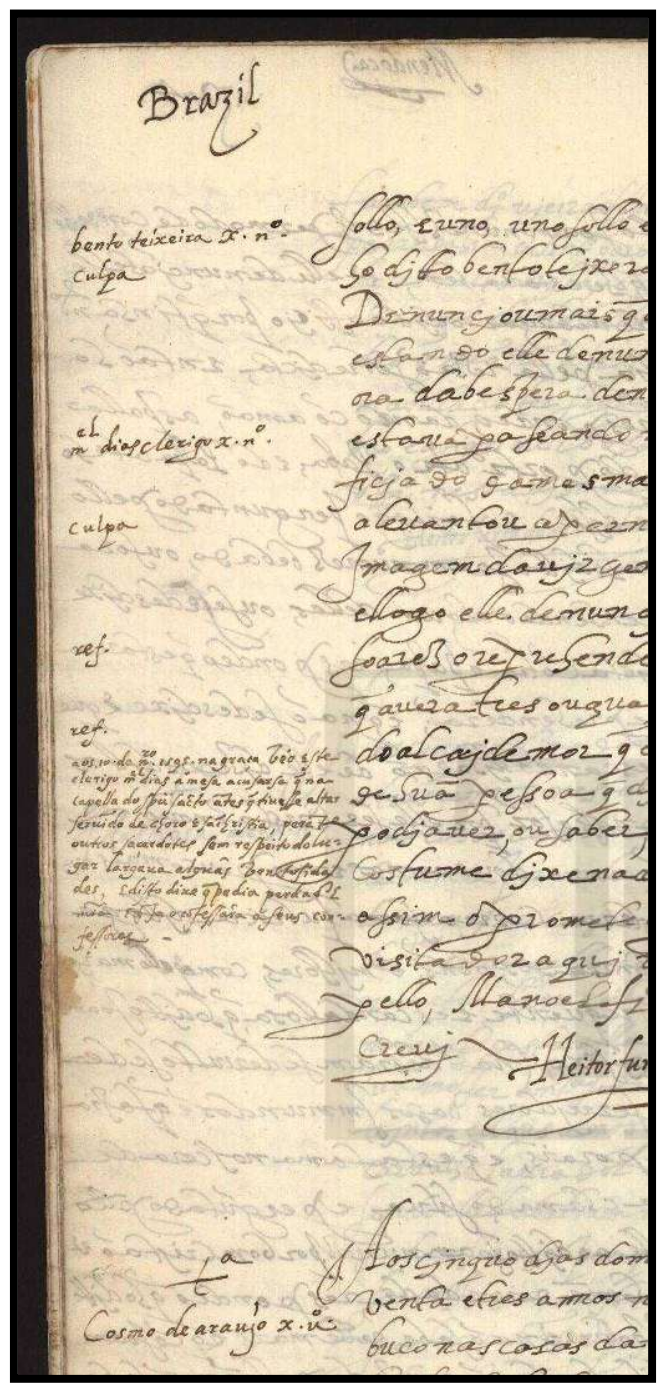

Fonte: Quarto Livro das Denunciações, fol. 24v 
No Quadro 2, encontram-se as grafias do visitador extraídas dos livros da Primeira Visitação:

Quadro 2: Grafias do visitador Heitor Furtado de Mendoça

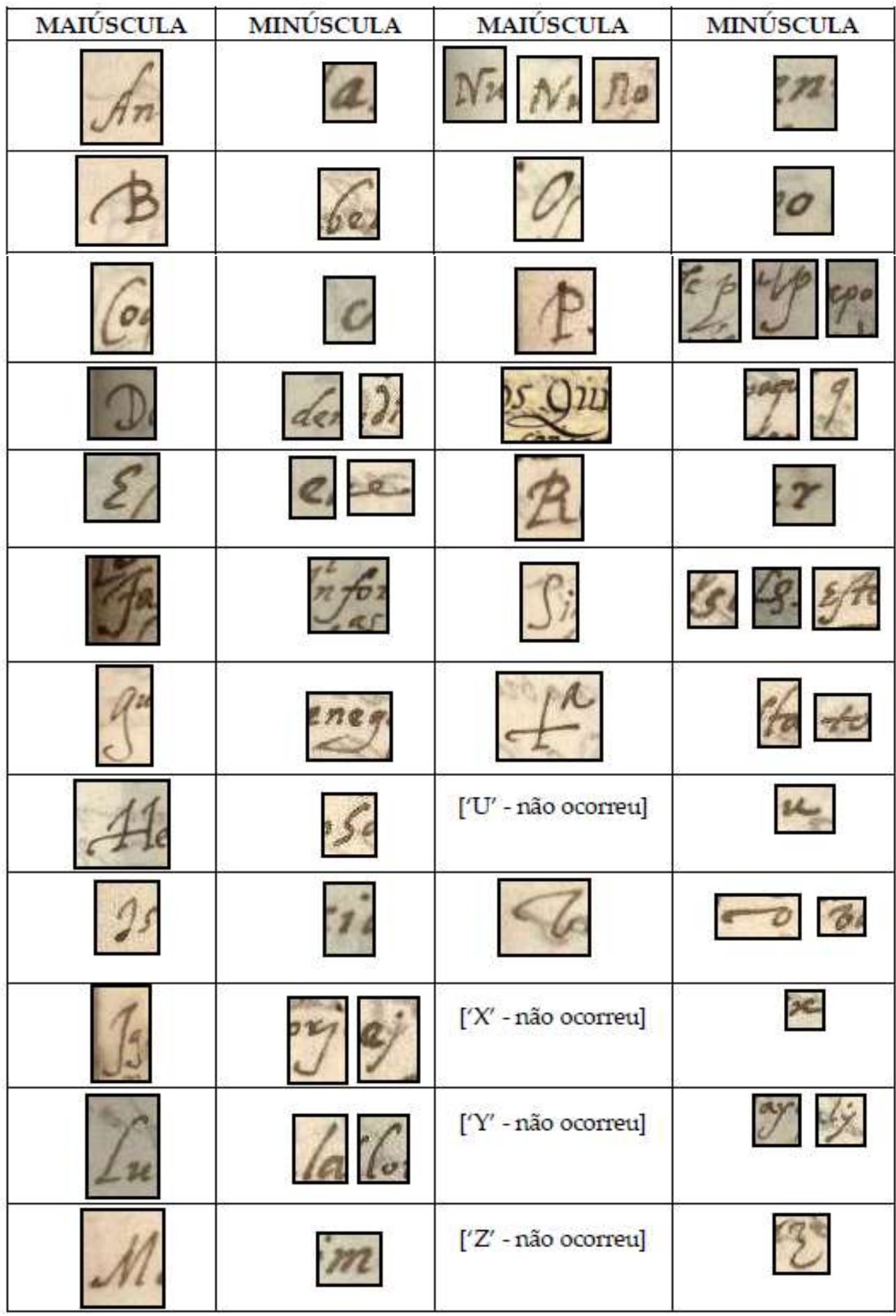

Fonte: Adaptado de Sartori (2016, p. 297-298) 


\subsection{Análise da escrita do visitador}

Nos títulos que encabeçam as várias partes do documento, o visitador fez uso de letras maiúsculas imperiais e também do tipo descrito por Steffens (1910, p. 23) como humanísticas dos livros. Nos títulos principais, ou na primeira linha dos títulos, são usadas as maiúsculas imperiais, enquanto em títulos de menor destaque e linhas abaixo da primeira se vê uma letra humanística, do tipo humanística dos livros. No primeiro fólio, por exemplo (Fig. 10), as duas primeiras linhas do título se encontram em letras maiúsculas imperiais e as duas linhas subsequentes estão em escrita humanística:

Figura 10: Título escrito pelo visitador

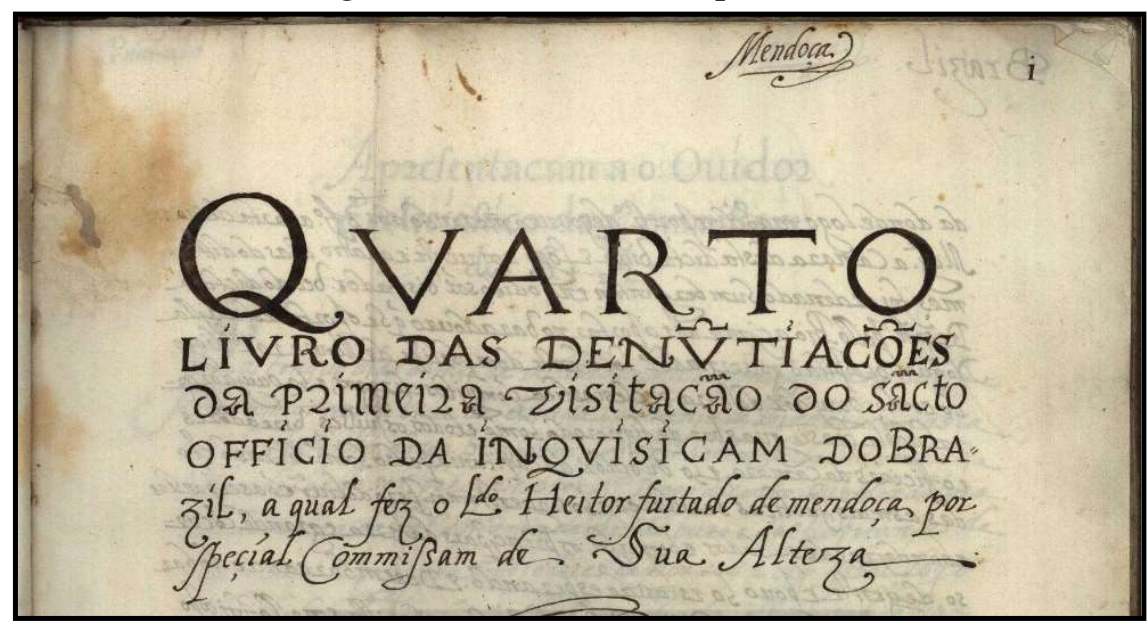

Fonte: Quarto Livro das Denunciações, fol. 01r

As maiúsculas imperiais possuem traços finos e uniformes, sem contrastes no peso. A altura e a largura das letras são proporcionais. A maior parte das letras possui serifas finas e simples, de traços retos. As barras das letras são retas, como se vê em ' $A^{\prime}$, ' $E^{\prime},{ }^{\prime} F^{\prime}$, ' $L '$ e 'T'.

Em alguns dos títulos, a primeira letra é mais alta ou tem o traço mais grosso. $\mathrm{O}$ ' $\mathrm{A}$ ' possui barra no centro e tem o ápice pontudo, sem serifa. ' $\mathrm{M}$ ' e ' $\mathrm{N}$ ' possuem ápice plano e serifado. A cauda do 'Q' é curva e ultrapassa levemente a 
linha média inferior. $\mathrm{O}$ 'E' possui geralmente traços frontais no braço superior e por vezes no braço central e ainda traço reverso no braço inferior. O 'L' também possui traço reverso no braço inferior. Encontram-se alguns casos de ' $\mathrm{C}$ ' com traço curvo frontal no semicírculo superior e traço curvo reverso no semicírculo inferior. Esses traços aparecem geralmente nas palavras que foram feitas com linha mais grossa que o geral. Nas palavras feitas com linha mais fina, o que predomina são serifas simples e finas, formadas por um único traço.

Os pontos dos 'I's são ornados, curvados para cima, e as vogais nasais são também ornadas com traços de tripla ondulação e também um traço curvo semelhante ao ômega grego.

Nos títulos em escrita humanística dos livros, contemplam-se letras verticais, assentadas, em sua maioria sem ligações. As hastes do 'b', 'd', ' 1 ', 'p', ' $\mathrm{q}$ ', ' $\mathrm{t}$ ' são retas. Muitas letras são formadas por mais de um traço, como é o caso do 'f', 'h', 'm', ‘n', 'p', 'u'.

O 'a' utilizado é o 'a' de dois níveis, sendo que o tipo que o visitador emprega é feito com um só traço, em que o bojo da letra não se fecha completamente e se encontra unido ao semicírculo superior.

É usado o 's' curto, embora também apareça o 's' longo nas palavras com 'ss'. Há ainda ocorrências de um 's' longo que apenas ultrapassa a linha média superior, de traçado semelhante a um ' $\mathrm{f}$ ' reto sem a barra. Encontra-se esse 's' ligado a letras subsequentes, um ' $t$ ' e também um 's' curto.

$\mathrm{O}$ ' $\mathrm{t}$ ' possui haste curta. Aparece o ' $d$ ' uncial, de único traço, com haste curvada para a esquerda, ao lado do 'd' reto. $\mathrm{O}$ ' $r$ ' usado é o meio ' $r$ ', do tipo redondo. Em algumas palavras, o ' $r$ ' encontra-se unido à barra do ' $t$ ' e do ' $\mathrm{f}$ '. $\mathrm{O}$ ' $\mathrm{f}$ ' é caudado e alcança a linha inferior.

Notam-se, em alguns títulos mais longos, linhas em escrita cursiva humanística. São justamente essas linhas que nos permitem avaliar com precisão que os títulos são de punho do visitador, e não do notário. A letra é a mesma que 
se encontra no termo de encerramento do livro (Fig. 7), escrito e assinado por Heitor Furtado de Mendonça. É uma escrita inclinada para a direita, de letras com hastes curvas, voltadas para a direita. Embora seja uma escrita inclinada, não é muito cursiva, possui poucas ligações e muitas letras são formadas por mais de um traço. Poderia se dizer que é uma cursiva intermédia entre uma escrita formal de títulos e a escrita corrente do visitador, utilizada nos lançamentos marginais, onde se vê basicamente o mesmo tipo de letras, mas escritas com mais ligações e abreviaturas, traçadas com menos esmero, formadas geralmente por um só traço.

É também do tipo cursiva humanística a escrita corrente do visitador. É este tipo de escrita que ele utiliza na folha de índice e nos lançamentos marginais à esquerda do corpo do texto, e ainda nas informações que põe na parte superior da folha - local, seu sinal e o número do fólio.

Sua letra é arredondada e inclinada para a direita; as hastes superiores das letras seguem geralmente essa inclinação (ver 'b', 'd', ' $f$ ', ' 1 ' e 's' longo no Quadro 2). Encontram-se muitas letras ligadas pela parte superior, e poucas serifas. Ocorrem vez por outra com as letras ' $\mathrm{p}^{\prime}$, ' $v^{\prime}$, ' 'j', ' $\mathrm{l}^{\prime}$, ' $\mathrm{t}$ ' e raramente com o 'd', em casos em que está curvado para a esquerda.

Muitas letras são semelhantes às da escrita do notário: 'a' simples, dois tipos de 'e', um deles semelhante ao ' $\mathrm{E}$ ' maiúsculo. $\mathrm{O}$ 's' longo e o 's' curto se alternam. $\mathrm{O}$ ' $\mathrm{f}$ ' é caudado. $\mathrm{O}$ 'b' é formado por um só traço e tem a haste curvada para a direita. $\mathrm{O}$ ' $\mathrm{h}$ ' tem um traçado semelhante ao da escrita do notário, de um ductus só, mas, no caso da mão do visitador, ele ultrapassa a linha média inferior.

Alternam-se um ' $d$ ' formado por dois traços, com a haste curvada para a direita, e um 'd' mais simples, de um único traço, com a haste curvada para a esquerda. $O$ ' $r$ ' utilizado é sempre o ' $r$ ' reto. $O$ ' $z$ ' é caudado. A cauda do ' $g$ ' tem apenas o traço para baixo; não sobe, formando uma laçada. $\mathrm{O}$ ' $\mathrm{t}$ ' é reto e tem haste curta. $\mathrm{O}$ 'p' é formado por dois traços, um para a haste e outro para o bojo. 
É utilizado com certa frequência o ' $y$ ', que pouco se vê na escrita do notário. Nota-se larga utilização do til para marcar a nasalidade, no lugar do ' $n$ ', e é também utilizado ligado à letra subsequente, forma que distingue claramente a escrita do visitador da escrita do notário, que não usa o til ligado à letra subsequente. $\mathrm{O}$ visitador utiliza-se de acentos agudos e crases, sinais que o notário praticamente não usa.

Os numerais utilizados são geralmente em algarismos arábicos, mas aparecem também alguns algarismos romanos, sobretudo a numeração dos fólios, em que se vê o número 1 escrito com o ' $\mathrm{I}$ ', ao lado de outros números escritos em algarismos arábicos (ver Fig. 5).

\section{ABREVIATURAS, SINAIS ABREVIATIVOS E LETRAS EM NEXO}

Na escrita do notário, as abreviaturas são utilizadas largamente. As duas formas de abreviatura mais utilizadas são: emprego de traço (geralmente ondulado) sobre a palavra, para marcar a supressão de letras, geralmente do interior da palavra (Fig. 11 e Fig. 12 a seguir); e emprego da última ou das duas últimas letras sobrepostas, após a sequência de letras suprimidas (Fig. 13 a seguir):

Figura 11: Abrev. de

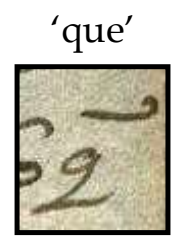

Fonte: TERCEIRO..., fol. $04 \mathrm{r}$
Figura 12: Abrev. de

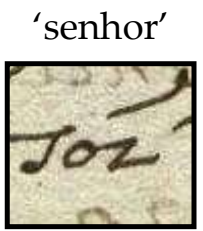

Fonte: TERCEIRO..., fol. $04 \mathrm{r}$
Figura 13: Abrev. de

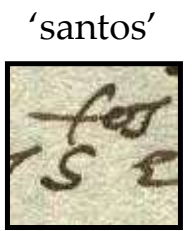

Fonte: TERCEIRO..., fol. $04 \mathrm{r}$ 
Na escrita do notário, aparece como abreviatura especial o scilicet (ver Quadro 3) e veem-se alguns nomina sacra: "Xpo", "xpããs", "xpouão", "xistouão", "Ihu".

Registrou-se ainda a junção da letra 'a' com a letra 'e', que foi transcrita com a forma 'æ'. Esse nexo, que representa o ditongo latino que já havia se monotongado, ocorreu em palavras como 'hæresia', 'prædestinação' e 'præsentes' (ver Quadro 3).

$\mathrm{Na}$ escrita do visitador, aparecem abreviaturas em profusão, nos lançamentos marginais. Os tipos utilizados são: letra sobreposta (Fig. 14 a seguir), abreviatura por supressão (Fig. 15 a seguir) e abreviatura por contração, com ou sem traço (Fig. 16); por vezes, é mantida apenas a primeira letra da palavra. O traço abreviativo, na letra ' 1 ', aparece cortando essa letra ao meio, o que ocorre sempre na abreviatura da palavra 'gonçalvez' (Fig. 17 a seguir):

Figura 14: Abrev. de 'Livro'

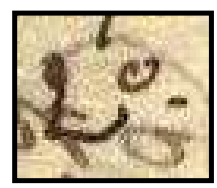

Fonte: TERCEIRO..., fol. $29 \mathrm{r}$
Figura 15: Abrev. de 'fólio'

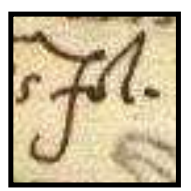

Fonte: TERCEIRO..., fol. $29 \mathrm{r}$
Figura 16: Abrev. de 'fernandez'

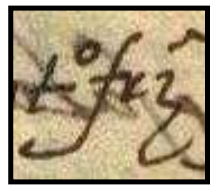

Fonte: TERCEIRO..., fol. $34 \mathrm{r}$
Figura 17: Abrev. de 'gonçalvez'

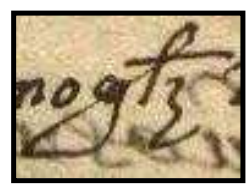

Fonte: TERCEIRO..., fol. $34 \mathrm{r}$

O visitador utiliza ainda alguns sinais abreviativos, representando 'que', 'ver', 'por'/'pro' e 'par', e também abreviatura para o scilicet e o esperluete (ver Quadro 3).

Ocorreu a junção das letras 'a' e 'e', na palavra 'frænético' (fol.115v). Tratase, nesse caso, de uma grafia pseudo-etimológica, já que a palavra em latim ('phreneticus') não possuía o ditongo. 
Quadro 3: Sinais abreviativos e letras em nexo

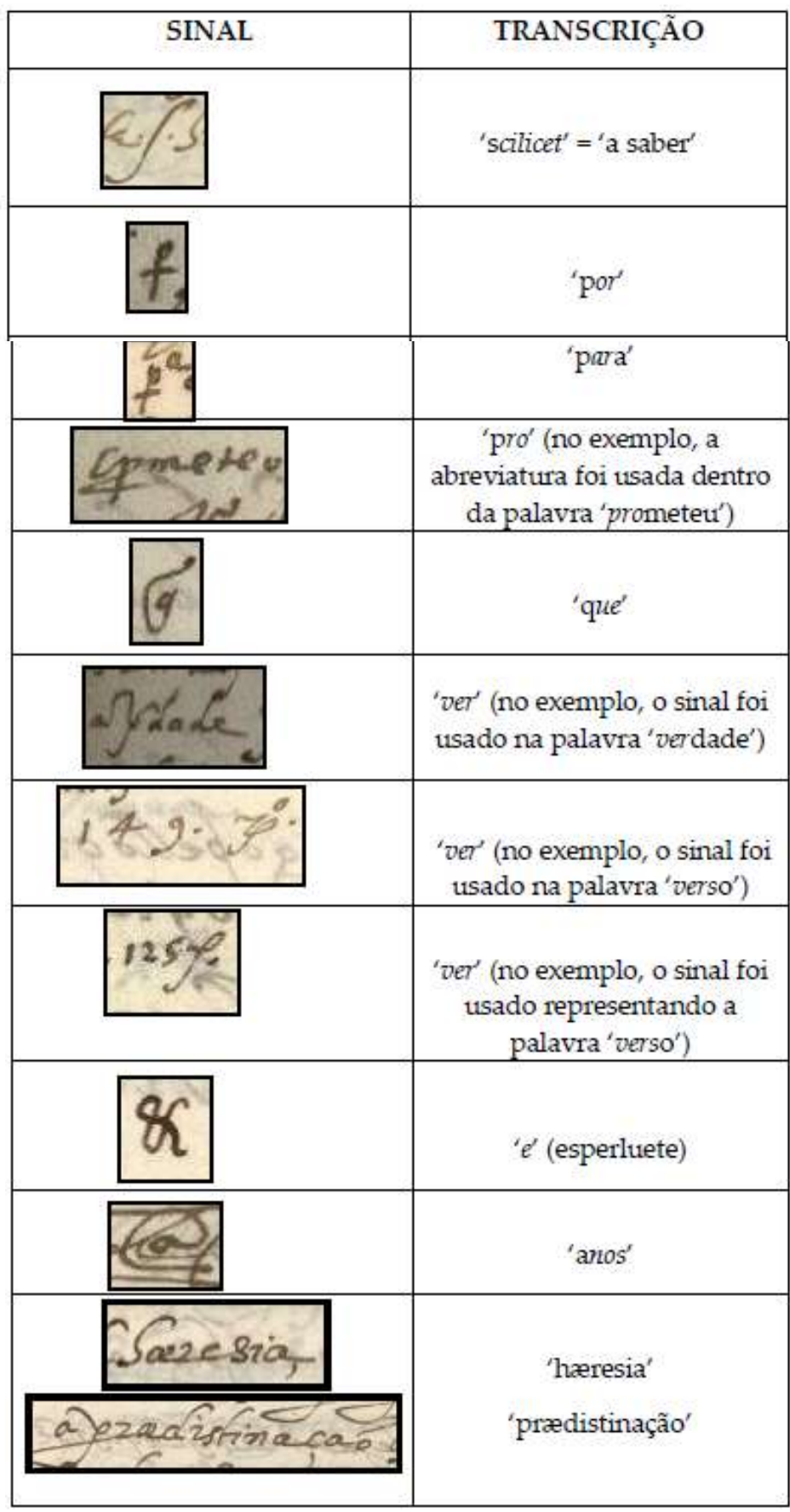

Fonte: Adaptado de Sartori (2016, p. 299; 318) 


\section{SINAIS DIACRÍTICOS NOS LIVROS DA PRIMEIRA VISITAÇÃO}

Os sinais diacríticos, tomados enquanto "sinais gráficos que conferem às letras ou grupos de letras um valor fonológico especial" (CÂMARA JR., 1985, p.94), serão aqui analisados de acordo com a nomenclatura adotada por Cambraia (2003), que distingue, em seu estudo dos diacríticos no Livro de Isaac (cód. ALC 461), os seguintes diacríticos: a cedilha, o ponto, o traço oblíquo, o traço ondulado e o traço horizontal, sendo que os sinais encontrados nos Livros da Primeira Visitação foram aqui agrupados de acordo com o valor fonológico que possuíam, chegando-se, assim, ao que se encontra no Quadro 4, a seguir:

Quadro 4: Sinais diacríticos

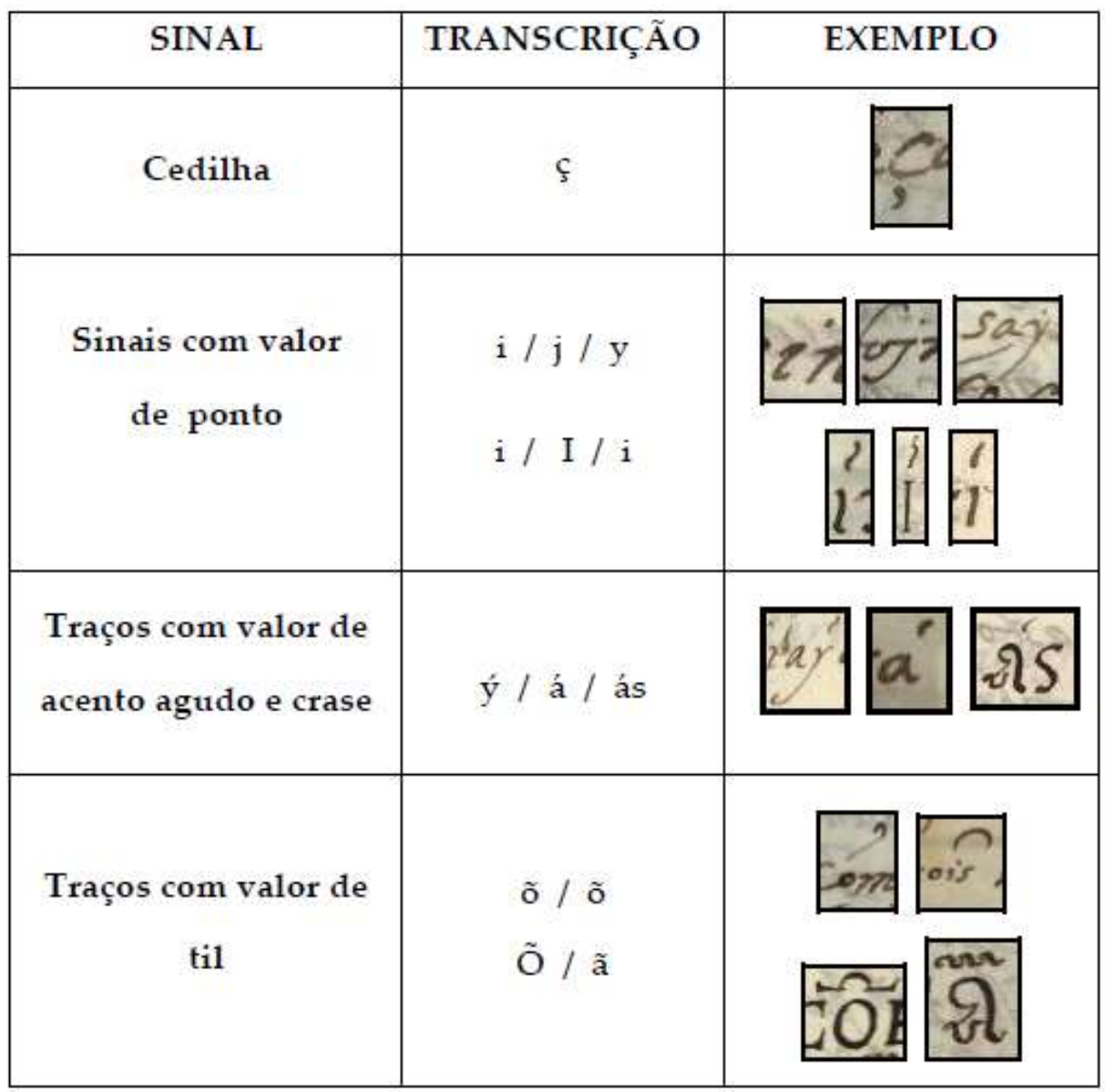

Fonte: Adaptado de Sartori (2016, p. 313) 


\subsection{Cedilha}

A cedilha foi encontrada abaixo da letra ' $c$ ', marcando o som de [s], tanto diante de 'a', 'o' e ' $u$ ', como diante de 'e' e 'i', como se pode observar nos exemplos a seguir, todos extraídos do Quarto Livro de Denunciações: 'mendoça' (fol.2r), 'espaço' (fol.18r), 'açuqueres' (fol.70r), 'conheçe' (fol.70v), 'denunçiação' (fol.244r).

Encontraram-se ainda alguns casos em que o 'ç' foi usado com som de [k], como nos seguintes exemplos, também extraídos do Quarto Livro de Denunciações: 'tamaraça' (fol.2r), 'çabeça' (fol.8r) e 'pratiça' (fol.32v). Nesses casos, foi também mantida a cedilha na edição. Ocorre também o inverso, o uso do ' $c$ ' com som de [s] sem a cedilha. Exs: 'capateiro' (fol.123v), 'mendoca' (fol.3v).

\subsection{Sinais com valor de ponto}

Os sinais encontrados com valor de ponto se diferenciam em dois tipos:

(i) O ponto (ou pingo) simples, usado, nos manuscritos editados, categoricamente sobre o ' $\mathrm{i}$ ' e o ' $\mathrm{j}$ ' minúsculos, e ainda, com pouca frequência, sobre o ' $y$ '. No caso do ' $y$ ', o ponto não foi reproduzido na edição.

(ii) Um traço ondulado, que parece um ponto ornado: inicia-se no ponto e é elevado. Aparece apenas nos títulos redigidos pelo visitador, em letra bem trabalhada, o que parece justificar o seu uso, que não estaria associado no manuscrito a qualquer função além da ornamental, como se pode ver pelo exemplo a seguir (Fig. 18). O traço foi transcrito como o ponto simples. 
Figura 18: Traços ondulados sobre o ' $\mathrm{i}$ '

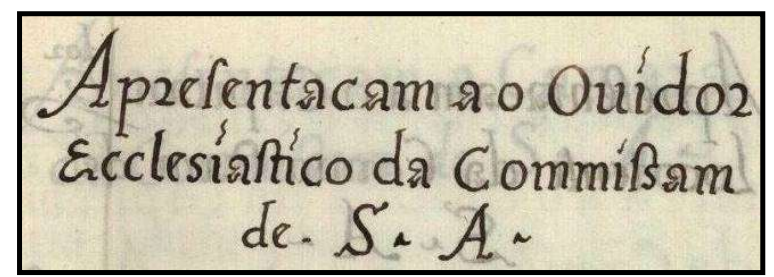

Fonte: Quarto Livro das Denunciações, fol.02r

Em uma palavra de grande recorrência no manuscrito, a palavra 'Brazil', escrita no cabeçalho dos fólios pelo visitador, ocorre um ponto com um traço inclinado geralmente mais reto do que ondulado, o qual foi transcrito igualmente como um ponto simples. Ainda que o desenho do traço se assemelhe mais, na maior parte das ocorrências, ao acento agudo, interpretou-se que, nesse caso, se tratava do mesmo traço ornamental dos títulos feitos pelo visitador, embora mais discreto, como se vê no exemplo a seguir (Fig. 19):

Figura 19: Escrita de "Brazil" pelo visitador

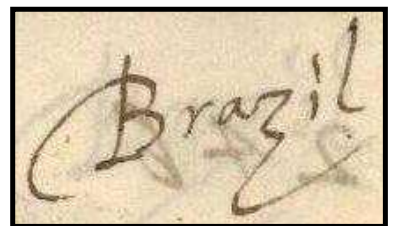

Fonte: QUARTO..., fol.246v

\subsection{Traços com valor de acento agudo e grave}

Um traço oblíquo, na maior parte das vezes reto, usado tanto com o valor de acento agudo, quanto com valor de acento grave, foi encontrado sobre vogais. Aparece poucas vezes na escrita do notário (ver Fig. 23), e ocorre com certa frequência na escrita do visitador (Fig. 20, Fig. 21 e Fig. 22). O traço foi transcrito sempre com o acento agudo, mesmo quando tinha valor de grave, como se pode observar nas transcrições das palavras a seguir: 
Figura 20: Transcrição: “Baýa" Figura 21: Transcrição: “ás" (às)

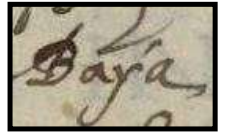

Fonte: QUARTO..., folha de índice-recto

Figura 22: Transcrição: "poderá"

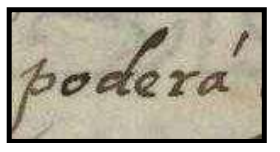

Fonte: QUARTO..., folha de índice-recto

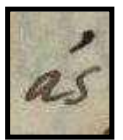

Fonte: QUARTO..., folha de índice-recto

Figura 23: Transcrição: "dá"

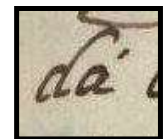

Fonte: QUARTO..., fol.07r

\subsection{Traços com valor de til}

O traço ondulado usado para marcar as abreviaturas não foi transcrito na edição; para indicar a existência da abreviatura, foram apenas postas em itálico as letras suprimidas. Dessa forma, os traços ondulados sobre palavras reproduzidos na edição foram aqueles usados com valor de til, como marca de nasalidade. Por outro lado, embora esse emprego do til seja largamente atestado, foram também observadas, só no Quarto Livro de Denunciações, mais de sessenta ocorrências de palavras em que o til não parece marcar nasalidade, sobretudo palavras terminadas com 'is', como se pode ver nos exemplos a seguir, retirados do Quarto Livro das Denunciações: 'maĩs' (fol.272), 'boĩs' (fol.268v), 'esteuẽz' (fol.259v), 'luĩs' (fol.247), 'crueĩs' (fol.235v), 'Reĩs' (fol.222), 'lopẽz' (fol.216v), 'pajnẽis' (fol.172r), 'costumẽs' (fol.165r), 'entendeĩs' (fol.165r), 'despoĩs' (fol.151r), 'corporaĩs' (fol.143r), 'geraĩs' (fol.136r), 'Princjpaĩs' (fol.136r), 'peĩs' (fol.118r), 'offjcjaĩs' (fol.23v). A palavra 'mais' é a que mais possui ocorrências com o uso do til, como se encontra na Fig. 24: 
Figura 24: Til usado na palavra 'mais'

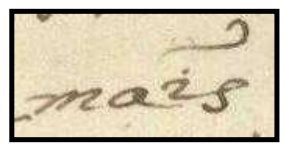

Fonte: QUARTO..., fol.272r

Com relação ao uso de traços como marca de nasalidade, distinguem-se, entre os exemplos presentes no Quadro 4, dos sinais diacríticos: um primeiro exemplo, feito pelo notário, com traçado semelhante ao do til atual; um segundo, feito pelo visitador, que tem a forma de um semicírculo; e outros dois, de traçado mais diferenciado. $\mathrm{O}$ terceiro exemplo tem um desenho bastante diferente, que se assemelha ao ômega, de caráter ornamental, usado, também como marca de nasalidade, pelo visitador, na palavra 'DENVTIACÕES', dentro do título que abre o Quarto Livro das Denunciações (Fig. 25), reproduzido a seguir:

Figura 25: Diferentes sinais usados como marca de nasalidade

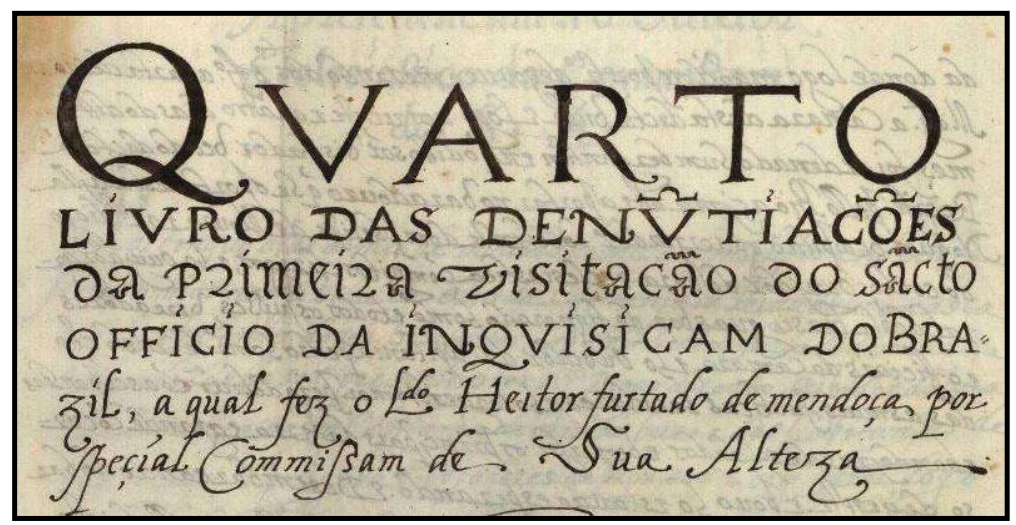

Fonte: Quarto Livro de Denunciações, fol.01r

O quarto exemplo é de um traço ondulado, que se vê no mesmo título anteriormente reproduzido (Fig. 25), sobre a letra 'a', nas palavras 'visitacão' e 'sãcto'. O uso do traço com valor de til parece ter razão estética, de ornamentação do título. Além deste fólio, o traço se vê apenas em outros fólios que possuem títulos feitos pelo visitador, também marcando nasalização. 


\section{CONSIDERAÇÕES FINAIS}

Nos livros que registram a primeira visita da Inquisição às terras brasileiras, destacam-se duas mãos, a do visitador Heitor Furtado de Mendonça e a do notário do Santo Ofício, Manuel Francisco. Ambos possuem um alto nível de letramento, o que se observa já pelo seu status social, sendo eles integrantes de uma elite culta, em que se encontram os religiosos. Entre os dados colhidos dos próprios livros aqui analisados, o Terceiro Livro de Confissões e o Quarto Livro de Denunciações, observa-se, nas assinaturas feitas ao final dos depoimentos, que $100 \%$ dos religiosos foram capazes de assinar o próprio nome nos livros inquisitoriais, o que não se observa em outros grupos sociais, como o dos assalariados, dos artesãos ou dos pequenos ofícios, dos quais 87\%, 76\% e 79\% mostraram-se capazes de assinar o nome, respectivamente.

O alto nível de letramento do notário e do visitador se confirma quando é analisada a sua escrita, e se observa a destreza e fluidez da escrita, bem como o domínio de uma caligrafia ensinada à época e registrada nos manuais de caligrafia. Ambos escrevem em uma escrita cursiva humanística, diferenciandose a escrita do notário da do visitador, uma vez que a primeira se aproxima mais do tipo italiana de chancelaria (STEFFENS, 1910), com letras arredondadas e hastes curvas e inclinadas para a direita, o que não se observa na escrita do visitador. Ainda assim, notário e visitador possuem uma caligrafia parecida, embora o traçado de algumas letras se diferencie substancialmente.

No que tange ao uso de abreviaturas, sinais abreviativos, letras em nexo e diacríticos, a escrita dos dois religiosos apresenta uma estrutura bastante semelhante, sendo os principais pontos de diferenciação a presença significativa do traço oblíquo com valor de acento agudo ou grave na escrita do visitador, praticamente inexistente na grafia do notário; e o uso em profusão do traço ondulado com valor de til para marcar a nasalidade das vogais na escrita do 
visitador, na escrita do notário geralmente substituído pelo uso do 'm' ou do ' $\mathrm{n}$ ' pós-vocálico.

Para além das diferenciações caligráficas entre a escrita do visitador e do notário, há ainda que se assinalar os diferentes estilos que se encontram em um mesmo documento: a escrita ornamental requerida pelos títulos, que apresenta inclusive outros tipos de letra, fazendo-se uso da humanística dos livros e ainda das maiúsculas imperiais, e a escrita desleixada e comprimida que se encontra nas notas feitas à margem esquerda dos fólios, pela mesma mão dos títulos, a do visitador. Em um meio-termo entre o excesso de ornamento de uma e o desleixo da outra, pode ser situada a escrita do notário.

\section{REFERÊNCIAS}

ARQUIVO NACIONAL DA TORRE DO TOMBO (ANTT). Site do ANTT. Lisboa: ANTT, 2005. Atualização diária. Disponível em: [http://antt.dgarq.gov.pt/]. Acesso em: 11/09/2012.

CÂMARA JR., JOAQUIM MATTOSO. Dicionário de linguística e gramática. 12. ed. Petrópolis: Vozes, 1985.

CAMBRAIA, César Nardelli. Crítica textual \& linguística histórica: a questão dos diacríticos. Caligrama, Belo Horizonte, n.8, p.21-40, nov. 2003.

CLAYTON, Ewan. La historia de la escritura. Trad. María Condor. Madrid: Siruela, 2015.

CRESCI, Giovan Francesco. Essemplare di piu sorti lettere. Venetia: Francesco Rampazetto, 1578. Disponível em: [http://gallica.bnf.fr/ark:/12148/bpt6k58909h/f17.image.r=.langEN]. Acesso em: 21/06/2015.

LEAL, João Eurípedes Franklin, SIQUEIRA, Marcelo Nogueira de. Glossário de Paleografia e Diplomática. Rio de Janeiro: Luminária: Multifoco, 2011.

QUARTO Livro das Denunciações da Primeira Visitação do Santo Ofício da Inquisição do Brasil, a qual fez o licenciado Heitor Furtado de Mendonça, por especial Comissão de Sua Alteza (1593-1595). In: ARQUIVO NACIONAL DA TORRE DO TOMBO, mf. 3077. Cópia microfilmada. Disponível em: [http://digitarq.dgarq.gov.pt]. Acesso em: 30/05/2011.

SARTORI, Ana. Pela pena do Santo Ofício: difusão social da escrita nas capitanias de Pernambuco, Itamaracá e Paraíba em finais de Quinhentos. 2016. 3 v. Tese (Doutorado em Língua e Cultura). Instituto de Letras, Universidade Federal da Bahia, Salvador. 
TERCEIRO livro das reconciliações e confissões da primeira visitação do Santo Ofício da Inquisição do Brasil, a qual fez o licenciado Heitor Furtado de Mendoca, por especial Comissão de Sua Alteza. [S.1.]: [s.n.], 1594-1595. 247 f. Microfilme. Disponível em: [http://digitarq.dgarq.gov.pt/ details?id=2318684]. Acesso em: 30/05/2011.

\section{A AUTORA E O PPGLinC}

\section{Ana Sartori}

Formei-me em Letras Vernáculas pela Universidade Federal da Bahia em 2003. Fiz o Mestrado em Linguística Histórica em 2010, pelo Programa de PósGraduação em Letras e Linguística (PPGLL), e o Doutorado na mesma área em 2016, pelo Programa de Pós-Graduação em Língua e Cultura (PPGLinC), ambos da Universidade Federal da Bahia. Atualmente, sou professora de Língua Portuguesa no Instituto de Letras da UFBA e membro do Programa para a História da Língua Portuguesa (PROHPOR), vinculando-me ao Projeto História da Cultura Escrita no Brasil (HISCULTE), estando dedicada, no âmbito do HISCULTE, ao estudo da difusão social da escrita e da língua portuguesa no Brasil. A pesquisa a que hoje me dedico teve suas origens nos estudos realizados durante o doutorado no PPGLinC. Foi ali, também, que se consolidaram as bases para a minha atuação profissional, a que hoje me dedico, no curso de Letras, voltando-me ao ensino da língua portuguesa no Brasil.

Nota do editor:

Artigo submetido para avaliação em: 04 de outubro de 2020.

Aprovado em sistema duplo cego em: 28 de dezembro de 2020. 